\title{
Study on Parameters Selection of Oil-Based Mud Formation Imaging Tool (OBIT) Based on FEM
}

\author{
Yue Liu \\ Wireline Logging R \& D Center, Logging Company Limited, CNPC, Beijing, China \\ Email: liuyuecn@hotmail.com
}

How to cite this paper: Liu, Y. (2019) Study on Parameters Selection of Oil-Based Mud Formation Imaging Tool (OBIT) Based on FEM. Open Journal of Yangtze Gas and Oil, 4, 43-58.

https://doi.org/10.4236/ojogas.2019.41004

Received: March 7, 2018

Accepted: January 27, 2019

Published: January 30, 2019

Copyright $\odot 2019$ by author and Scientific Research Publishing Inc. This work is licensed under the Creative Commons Attribution International License (CC BY 4.0).

http://creativecommons.org/licenses/by/4.0/ (c) (i) Open Access

\begin{abstract}
In a typical oil-based mud environment, the borehole fluid and mud cake are highly resistive and will not permit any significant current flow from the tool to the formation. In order to overcome the high insulation effect of the medium, measurement current must be injected at a relative high frequency since most of the conduction is due to capacitive coupling. In this paper, an OBIT numerical model based on four-terminal method was established to study the tool responses during the measurements. The influences of tool parameters, such as the area and distance of current-injector electrodes, inject frequency, distance of button sensors, standoff and electrical properties of borehole fluid, the tool responses, were investigated and the tool optimization was discussed.
\end{abstract}

\section{Keywords}

Oil Based Mud, Image Logging, Capacitive Coupling, Four-Terminal Method

\section{Introduction}

High resolution image logging technologies are well-known among geologists and engineers because the sufficiently detailed images can provide useful structural and stratigraphic information in many geological settings [1] [2] [3]. Micro-resistivity imager, part of image logging technologies, has been widely used in water based mud well logging [4] [5] since it was commercialized in 1980s and rapidly developed in 1990s. Oil-based or nonconductive synthetic based muds are widely applied as more and more special and deep-water reservoirs are explored [6] [7] [8]. Compared with conventional water based mud, oil based mud can enhance the stability of borehole, reduce drilling risk, and increase efficiency 
of drilling. However, the nonconductive environment presented by the oil based mud constitutes a major challenge to conventional micro-resistivity imagers based on micro-laterolog principles, such as FMI, XRMI and Star [9], which depends on current flow from a source to a return electrode with relatively large spacing. Many oilfield service companies have studied and developed their own tools for oil based mud well logging consecutively since 2000s [10] [11] [12] [13] [14]. Schlumberger and Halliburton designed their tool based on four-terminal method. A relative high frequency alternating current was injected into the formation through capacitive coupling between two current-injector electrodes. The potential difference, measured by a pair of sensors set in the middle of injector electrodes, contains formation information. Formation resistivity can be obtained by calculation. Baker applied capacitive coupling method. The measurement principle is similar to the micro-resistivity imagers. Relatively high alternative displacement currents flow from a source to a return electrode with formation. Schlumberger has developed a new generation Oil based mud imager NGI [15]. The resolution of images obtained by has been significantly improved; however, the measurement depth is relatively shallow, $0.2 \mathrm{in}$, as the measurement is performed entirely on the tool pad. Baker Hughes also improved their tool based on the first generation imaging tool [16]. No matter what kind of methods they used, the displacement current is generated in the formation through capacitive coupling; thus the current injects into the formation. With measuring formation related parameters, such as potential difference or current, we can obtain formation resistivity. In this paper, the four-terminal method is chosen to design the tool OBIT and a finite-element four-terminal model is established to study influences of parameters on tool responses.

\section{Numerical Modeling}

The principle of measurement is based on the four-terminal method. The schematic in Figure 1 shows a pad applied against the borehole wall with possibly a small standoff. A relative high frequency alternating current, I, is injected into the formation between two current-injector electrodes A and B located above and below five pairs of small button sensors. The potential difference $\delta V$ is measured between the button sensors $\mathrm{C}$ and $\mathrm{D}$. As we have known I and $\delta V$, we can calculate the resistivity of the formation between $\mathrm{C}$ and $\mathrm{D}$.

Finite element method has been used in modeling and simulation for many decades due to its capabilities of adapting complicated geometry. Therefore, 3D finite-element models of the OBIT have been developed and used for tool properties analysis.

Figure 2 shows the geometry of the 3D OBIT mode. In the OBIT model, a homogenous medium represents the geological formation. The cylindrical borehole is filled with oil based mud. An OBIT pad is applied on the borehole wall to measure formation resistivity. The geometry and the electrical properties of the OBIT pad can be adjusted for different simulation purposes. In Figure 2, the diameter of the borehole is $300 \mathrm{~mm}$. The length, width and thickness of the pad 


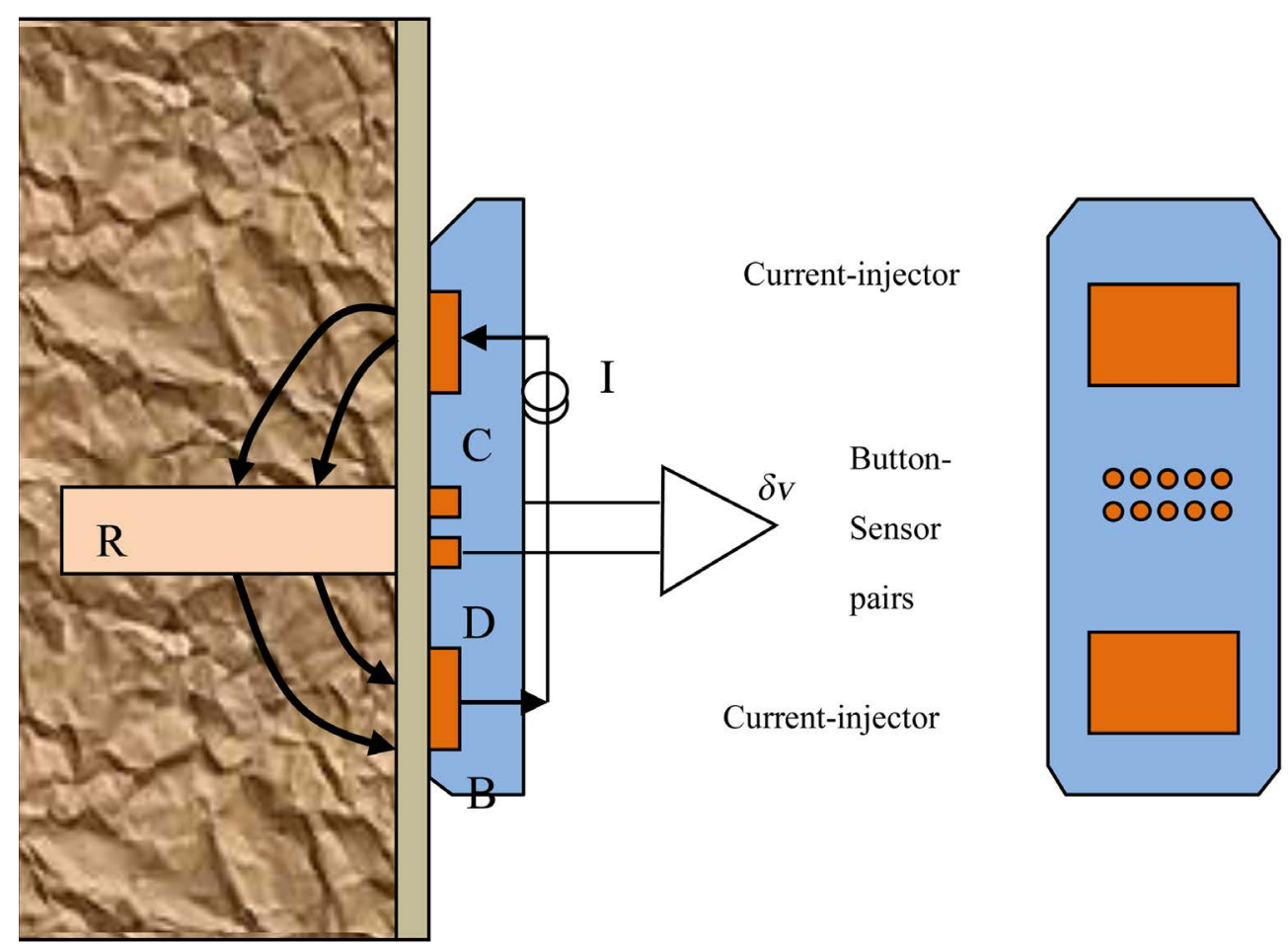

Figure 1. Principle of measurement.

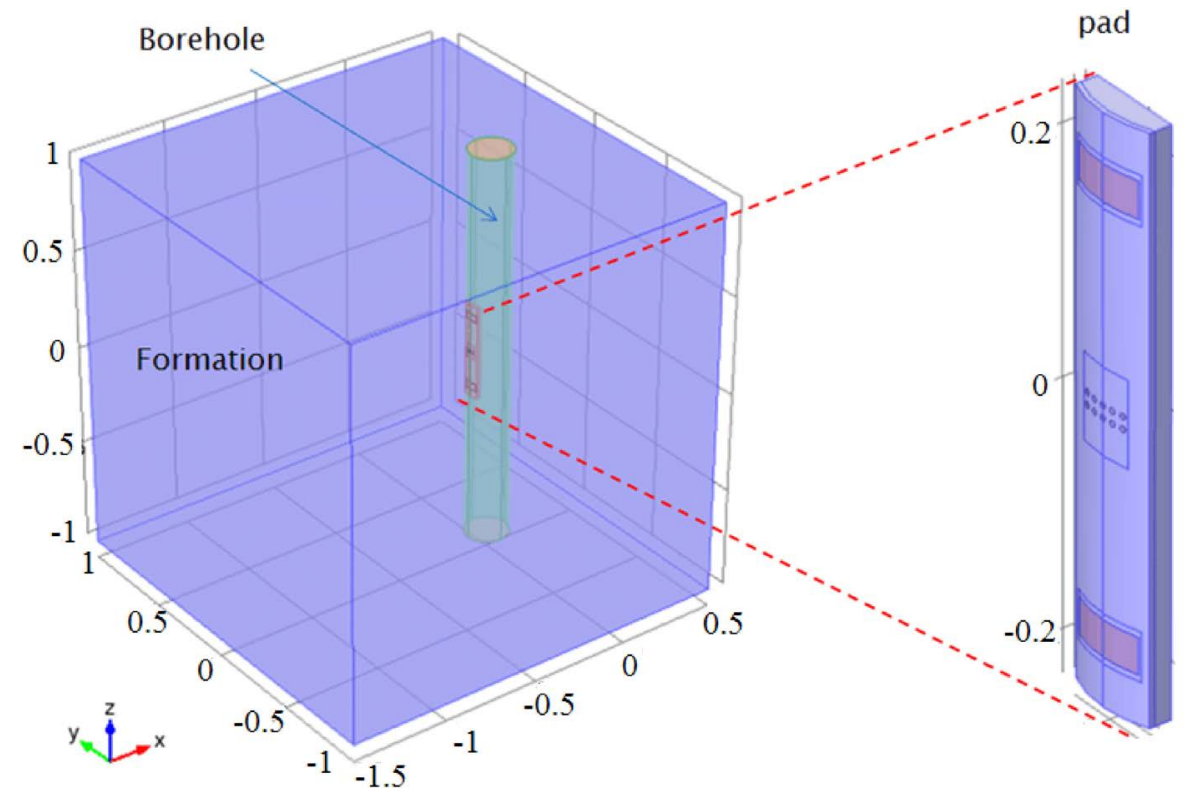

Figure 2. 3D OBIT model.

are $370 \mathrm{~mm}, 80 \mathrm{~mm}$ and $27 \mathrm{~mm}$ respectively. The length and the width of the current electrodes are $80 \mathrm{~mm}$ and $50 \mathrm{~mm}$ respectively. The distance between centers of the two current electrodes is $320 \mathrm{~mm}$. The diameter of the measurement button is $10 \mathrm{~mm}$ and the distance between measurement button centers is $20 \mathrm{~mm}$. The electrical properties of the model can be adjusted for different simulation purposes. Typical values used in the OBIT numerical simulations are listed in Table 1. 
Table 1. Electrical properties of the OBIT model.

\begin{tabular}{ccc}
\hline Material & Resistivity $(\Omega \cdot \mathrm{m})$ & Relative permittivity/1 \\
\hline Formation & $0.1 \sim 10,000$ & 5.0 \\
Oil-based mud & $10^{6}$ & 5.0 \\
OBIT Pad & $10^{16}$ & 3.2 \\
Current pads and voltage electrodes & $1.67 \times 10^{-6}$ & 1.0 \\
\hline
\end{tabular}

To obtain the right simulation results by using finite-element method, computation domains have to be specified in which numerical simulations can be implemented. Setting correct boundary conditions are essential to get correct results. In the model mentioned above, the following boundary conditions were applied: The exterior surface of the model was set as electric insulation. This boundary condition means that no electric current flows into the boundary. The current electrodes were set as current terminals in the OBIT model. The terminal boundary is assumed to be connected to an external circuit for providing the predefined current. The metal part of the pad body was set as ground. Ground means that there is a zero potential on the boundary.

Figure 3 shows the mesh of the model. The mesh consists of 532,880 tetrahedral elements, 54,318 triangular elements, 3104 edge elements and 172 vertex elements. In order to increase the accuracy of simulation, the mesh of the OBIT pad and the borehole are much denser than that of the formation.

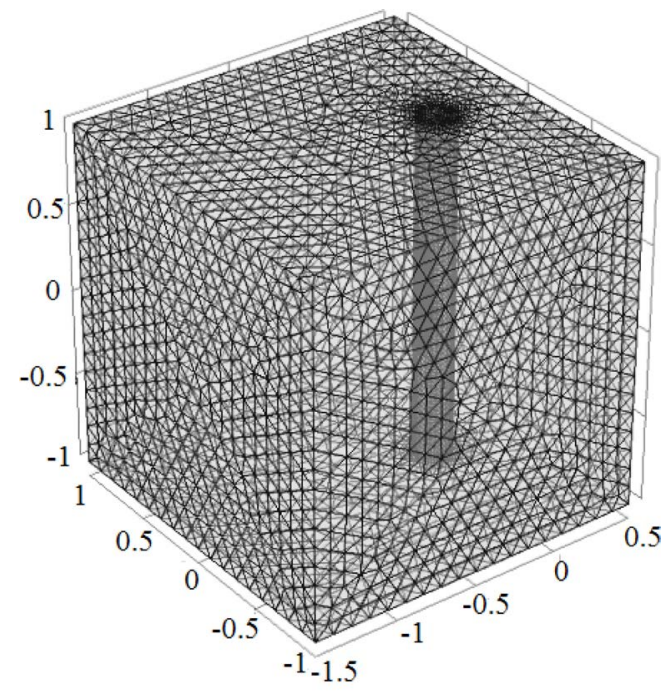

Figure 3. Mesh of the 3D model.

\section{Simulation Results}

\section{1) Electric field distribution in the formation and borehole}

Based on the OBIT model shown in Figure 2, the current density and electric field distribution in both the formation and the borehole have been simulated. The frequency used in the model here was $10 \mathrm{k} \mathrm{Hz}$ and the injecting current was $1 \mathrm{~mA}$. The material properties in Table 1 were used. Figure 4 shows the current 
density (in logarithm scale) distribution on an $x-y$ plane $(z=0)$ and a $x-Z$ plane $(y=0)$. The amplitude of current density has been color coded. Red color represents large current density. It can be seen that the current in the borehole is rather small except the area near the two current pads, which indicates that most of the current is able to penetrate the resistive oil based mud into the formation.

Figure 5 shows the electric field distribution. In contrast to the current density, the electric field in the borehole is much larger than that in the formation. That is because of the higher resistivity of the oil-based mud in the borehole.

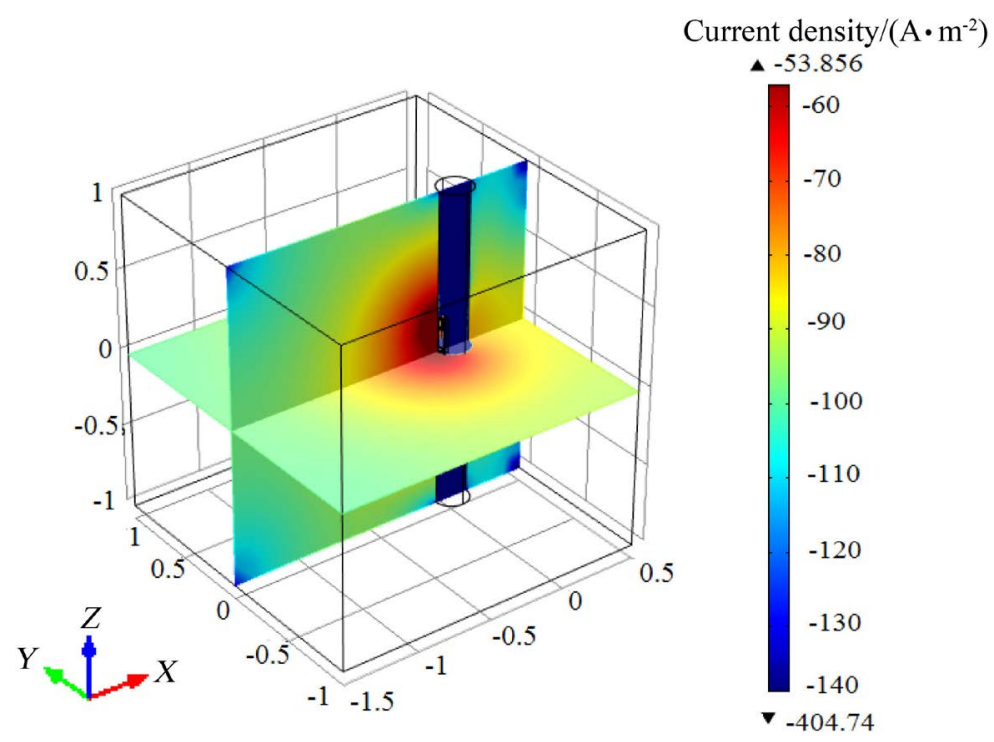

Figure 4. Current density distribution.

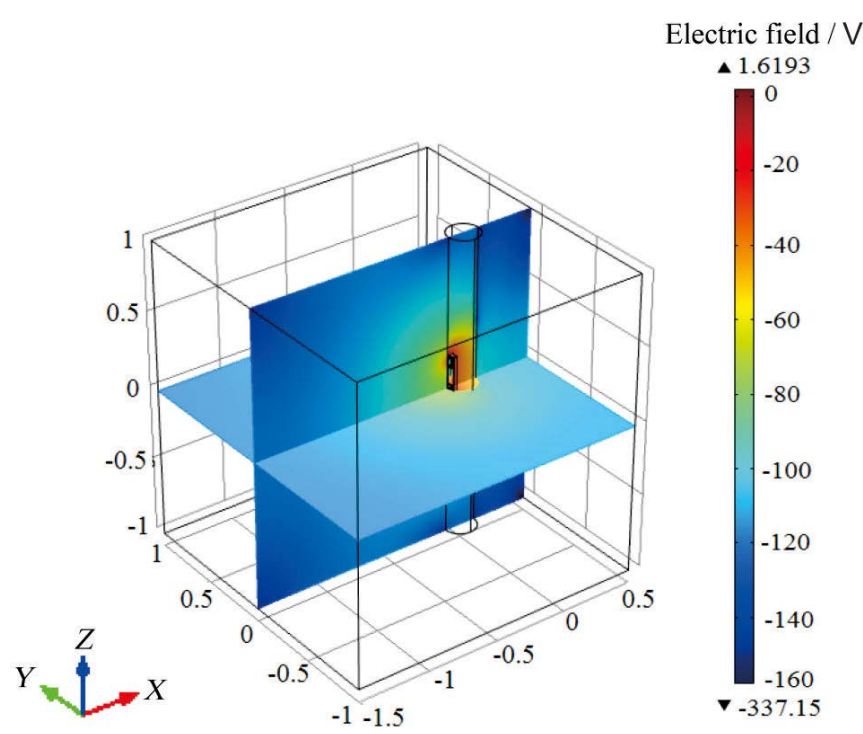

Figure 5. Electric field distribution.

\section{2) Influence of current-inject and measurement button electrodes}

The influence of the current electrode and measurement button dimension on the OBIT response will be discussed in this section. In the following simulations, we kept the distance between the centers of current electrodes and the distance 
between measurement buttons constant. Only the dimension of the current electrodes and the measurement button were changed. Figure 6 shows the voltage difference on measurement buttons $d v$ versus formation resistivity for different current electrode lengths. In this model, the injecting current was kept as $1 \mathrm{~mA}$ and the frequency as $10 \mathrm{kHz}$. It can be seen from Figure 6 that the $d v$ slightly decreases with the decrease of the current electrode length. However, the $d v$ is not very sensitive to the current electrode length on the whole as long as a constant injecting current is kept on the electrodes. Figure 7 shows the $d v$ versus

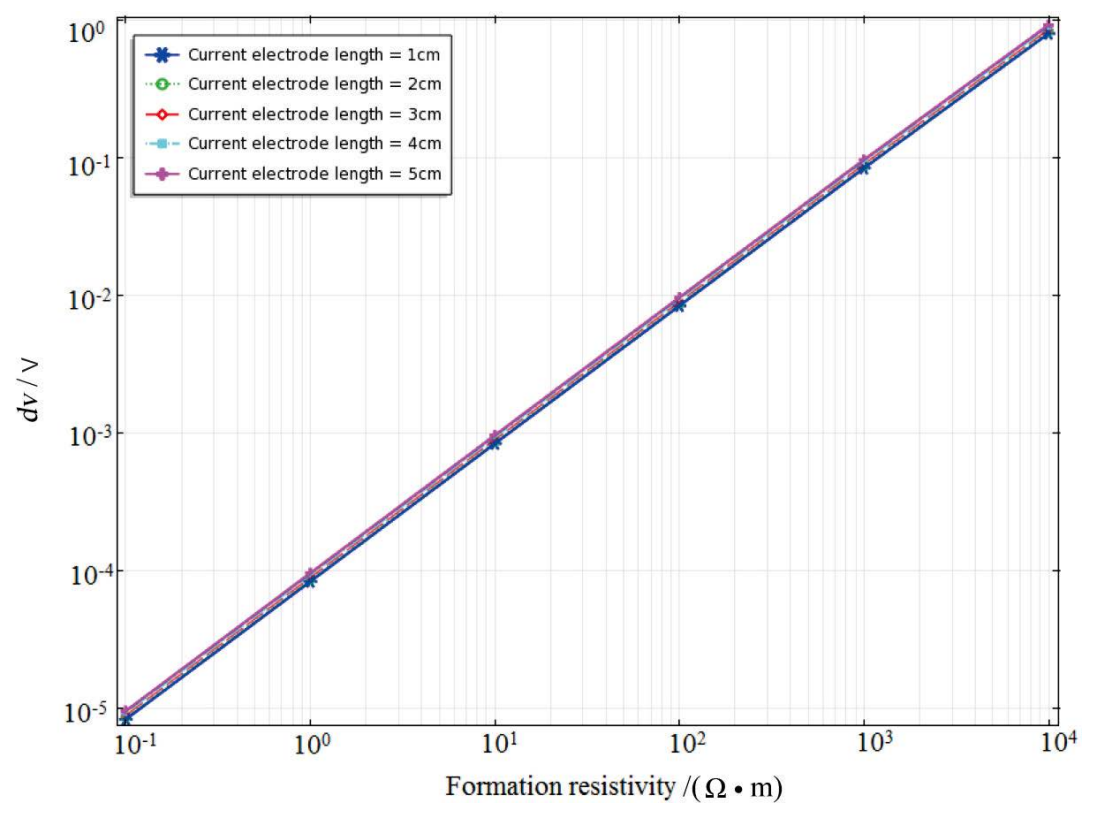

Figure 6. OBIT response $(d v)$ versus formation resistivity for different current electrode lengths.

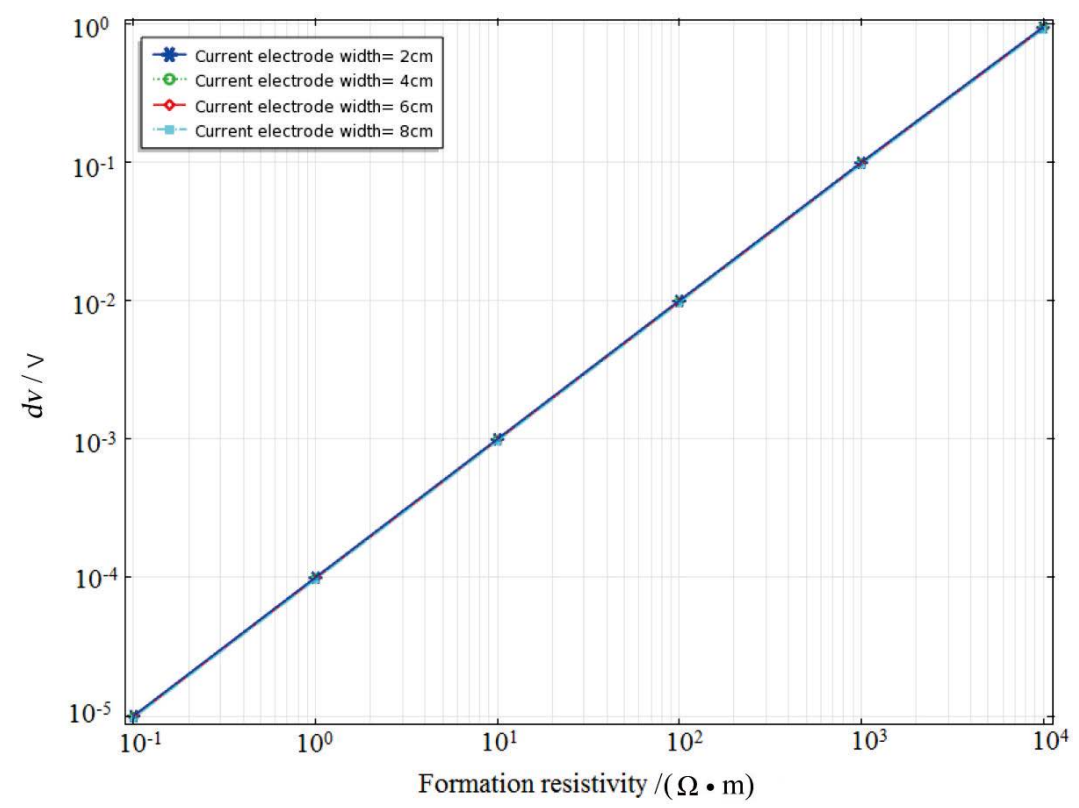

Figure 7. OBIT response $(d v)$ versus formation resistivity for different current electrode widths. 
formation resistivity for different current electrode widths. It can be seen that the $d v$ is not sensitive to the current electrode width as long as the injecting current is kept constant.

Figure 8 and Figure 9 show how the electrode impedance changes with current electrode dimension. Figure 8 shows the electrode impedance versus formation resistivity for different electrode length and Figure 9 for different electrode widths. It can be seen that the electrode impedance increases significantly with the decrease of the electrode size. The higher the electrode impedance is, the

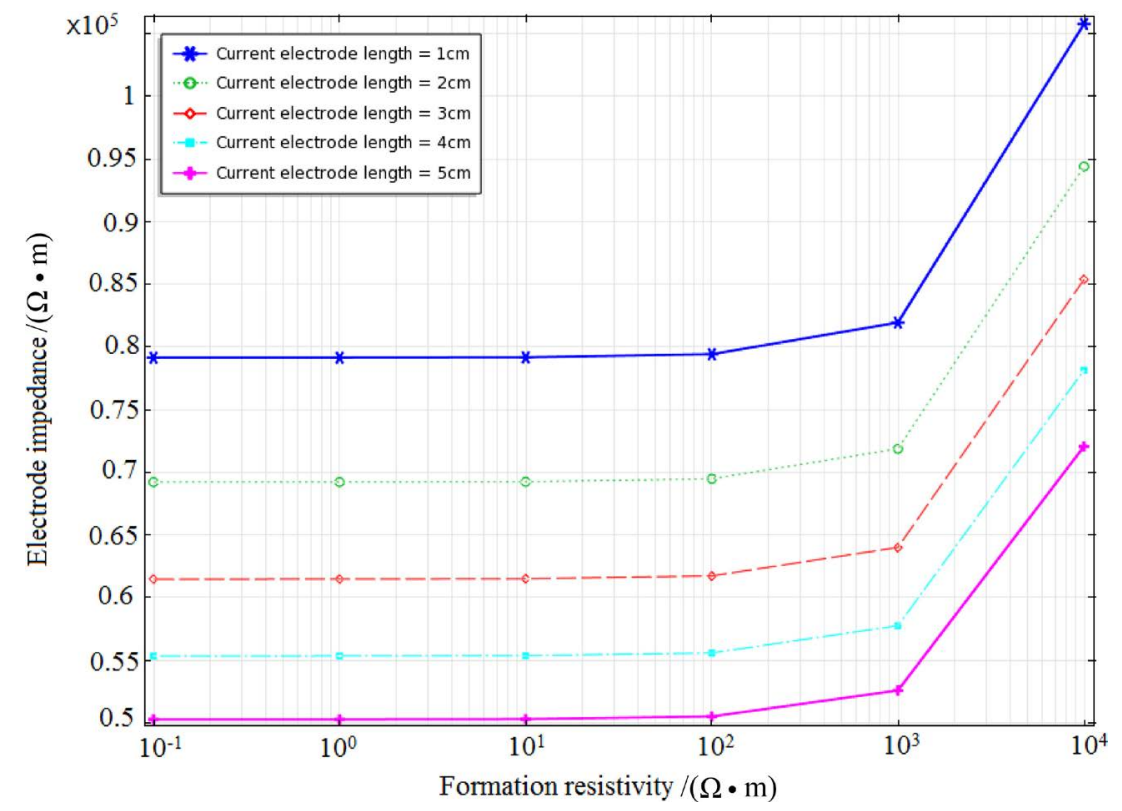

Figure 8. Electrode impedance versus formation resistivity for different current electrode lengths.

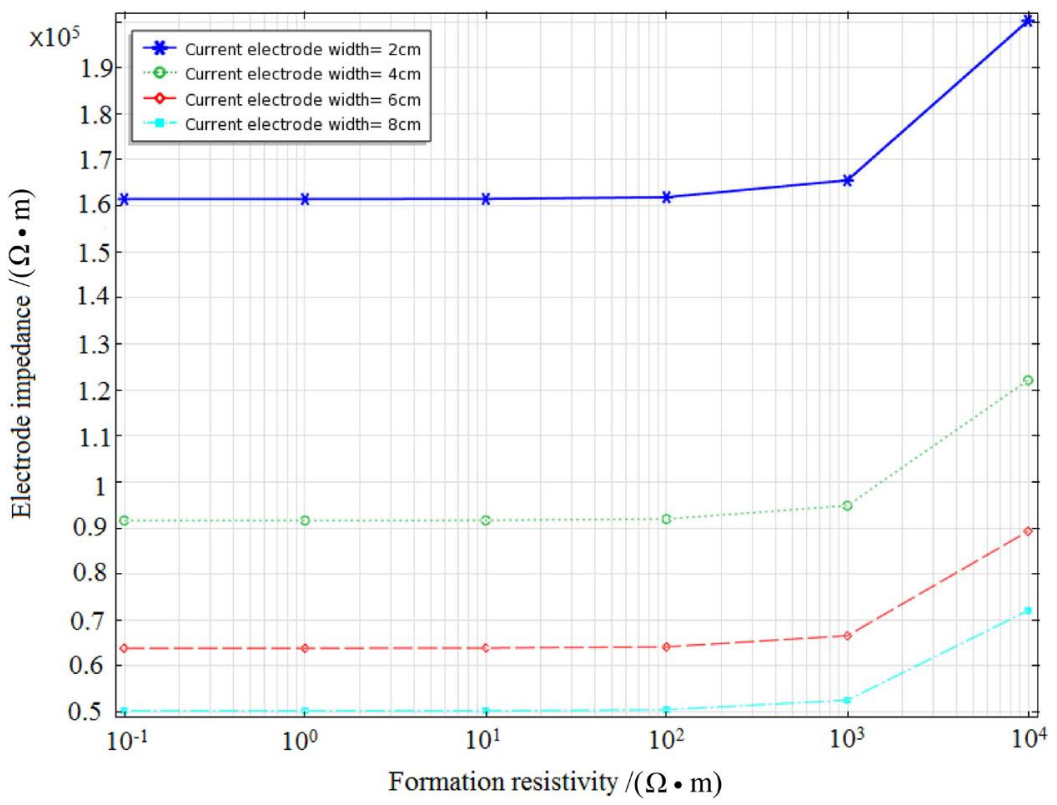

Figure 9. Electrode impedance versus formation resistivity for different current electrode widths. 
higher the voltage on the current electrode, which is needed in order to keep a constant transmitting current.

Figure 10 shows the $d v$ versus formation resistivity for different measurement button sizes. It can be seen that the $d v$ increase slightly with the increase of the measurement button diameter. It is because that the bigger the diameter of the measurement button is, the better the coupling between measurement buttons and formation is.

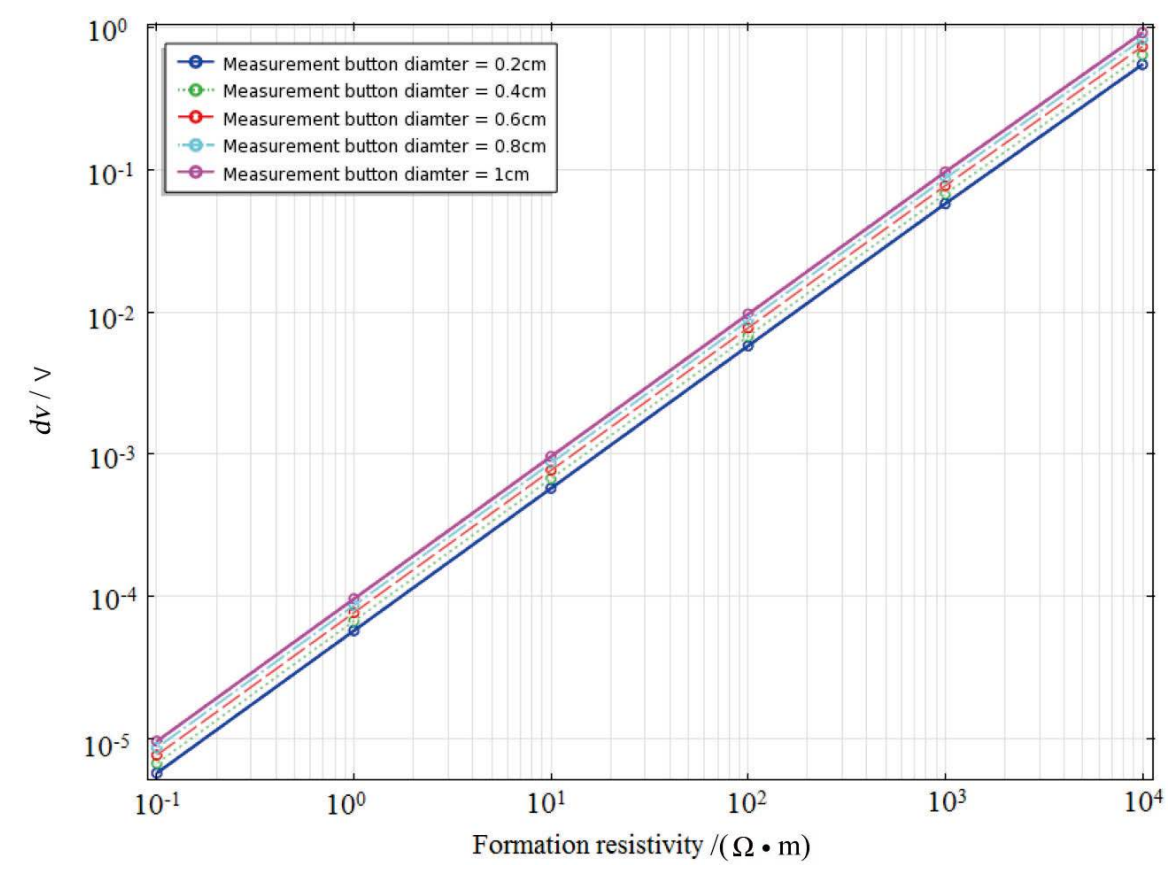

Figure 10. OBIT response $d v$ versus formation resistivity for different measurement button diameters.

\section{3) Effect of resistivity and dielectric constant of oil based mud}

The high resistance oil-based mud prevents the current flow from the current pads to the formation. Therefore, it is important to investigate the effect of resistivity and dialectical constant of the oil based mud on the OBIT response. The resistivity of oil based mud was set to be $10^{4}, 10^{5}, 10^{6}$ and $10^{7} \mathrm{ohm} \cdot \mathrm{m}$ respectively; The other material properties remain the same values in Table 1. Figure 11 shows the OBIT response versus formation resistivity for different oil based mud resistivities. It can be seen that when the mud resistivity is comparable with formation resistivity, the relationship between the OBIT response and the formation resistivity gets worse (see the blue curve in Figure 11). When the resistivity of mud is much larger than the formation resistivity, the OBIT response is not sensitive to the mud resistivity. That is because the impedance of oil based mud is mainly dominated by its capacitive impedance which is related to its dielectric constant instead of resistivity.

Figure 12 shows the OBIT response versus formation resistivity for different dielectric constants of oil-based mud. The dielectric constant of the mud was set to be $2,4,6,8$ and 10 respectively, and the other material properties in the model 
remain the same values in Table 1. From Figure 12, it can be seen that the OBIT response increases with the increase of the dielectric constant of the mud. That is because the capacitive impedance between the current electrodes and the formation surface decreases with the increase of the dielectric constant of the oil based mud.

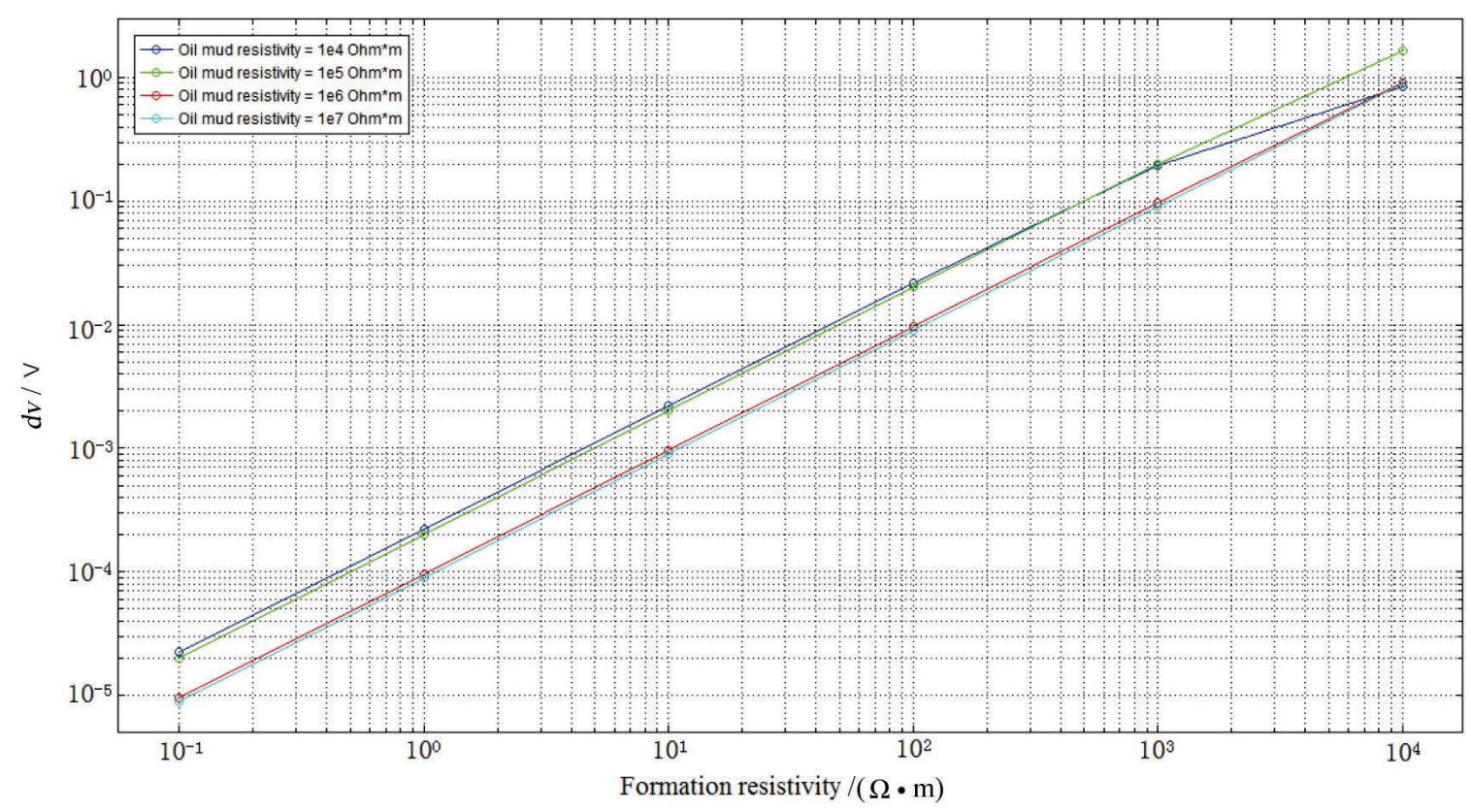

Figure 11. OBIT response versus formation resistivity for different oil based mud resistivity.

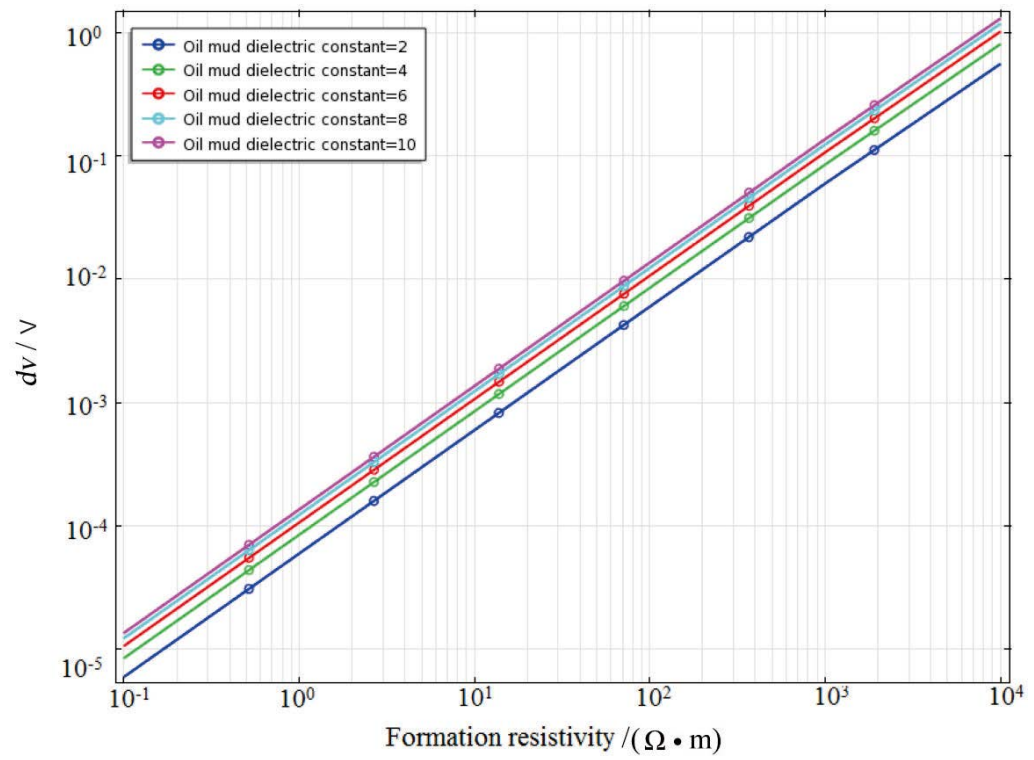

Figure 12. OBIT response versus formation resistivity for different oil based mud dielectric constants.

4) Effect of the thickness of oil based mud layer (standoff distance)

Standoff distance usually refers to the thickness of the oil layer between the current electrodes and the formation wall. Figure 13 shows the OBIT response versus formation resistivity for different standoff distances. The standoff distance 
was set to be $2,4,6,8$ and $10 \mathrm{~mm}$ respectively. It can be seen that the OBIT response decreases with the increase of the standoff distance. That is because the capacitive impedance between current electrodes and formation wall increases with the increase of the standoff distance. Accordingly, the current flow through the formation decreases and the current leakage inside the OBIT pad increases.

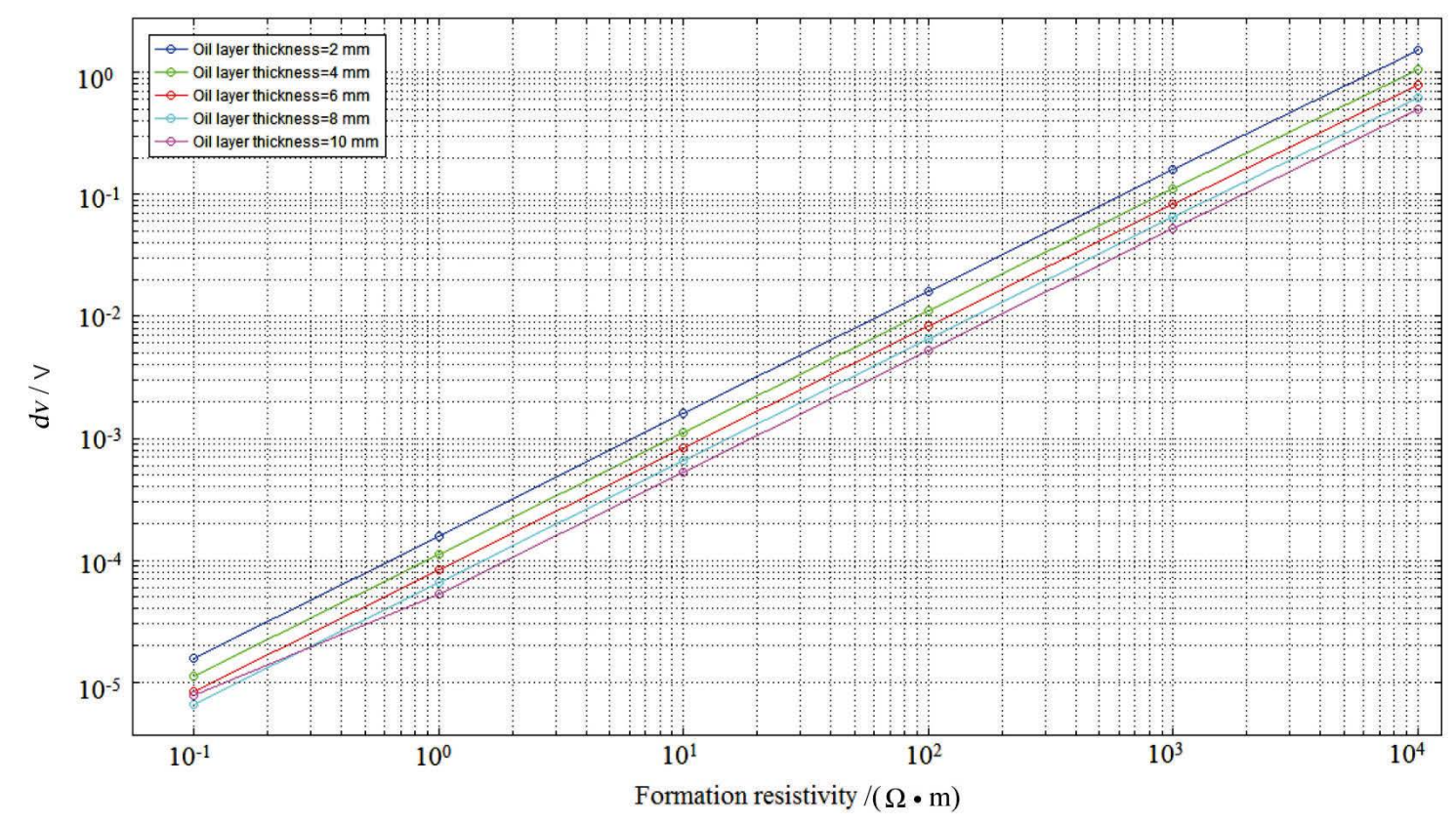

Figure 13. OBIT response versus formation resistivity for different standoff distance.

\section{5) Effect of the borehole diameter}

Figure 14 shows the OBIT response varying with formation resistivity for different borehole diameters. The borehole diameter was set to be 10, 20, 30, 40, 50

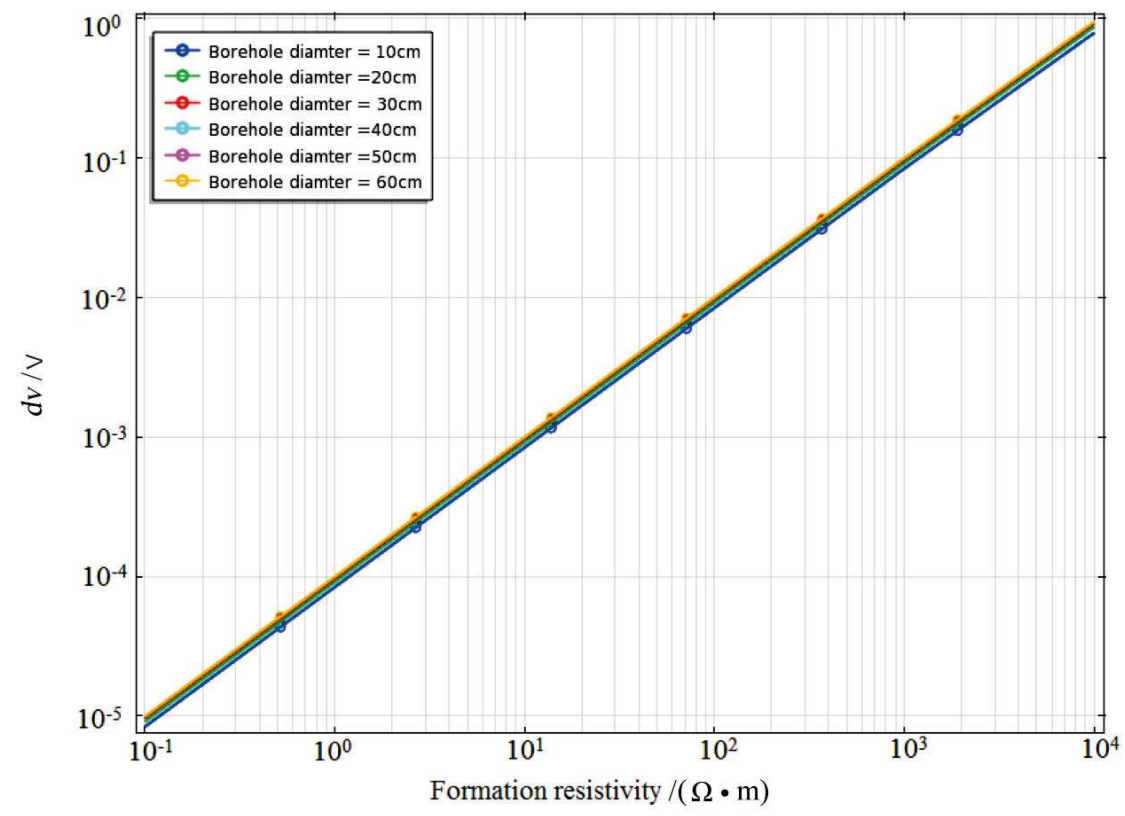

Figure 14. OBIT response versus formation resistivity for different borehole diameters. 
and $60 \mathrm{~cm}$ respectively. It can be seen that the OBIT response is not very sensitive to the borehole diameter. This is because that the OBIT pad is very close to the borehole wall and most of the transmitting current is injected into the formation facing the OBIT pad.

\section{6) Effect of injecting current frequency}

As mentioned previously, an alternating current with certain frequency has to be used in order to penetrate the highly resistive oil based mud. If the frequency is too low, then the impedance between electrodes and formation will be very high, and the received signal on measurement button will be accordingly small. If the frequency is too high, the impedance of the insulating part of the pad body will be significantly reduced and the received signal on the measurement buttons will be no longer linearly changed with the formation resistivity at high resistivity. Therefore, it is important to investigate the frequency effect on the OBIT response.

The model geometry of Figure 2 and material properties in Table 1 are used, while the OBIT response $d v$ versus formation resistivity at different frequencies is shown in Figure 15, assuming an injecting current of $1 \mathrm{~mA}$ is used. It can be seen that the responses at $1 \mathrm{kHz}$ and $10 \mathrm{kHz}$ have good linearity. Therefore, the proper frequency for the OBIT should be within $1 \mathrm{kHz}$ to $10 \mathrm{kHz}$.

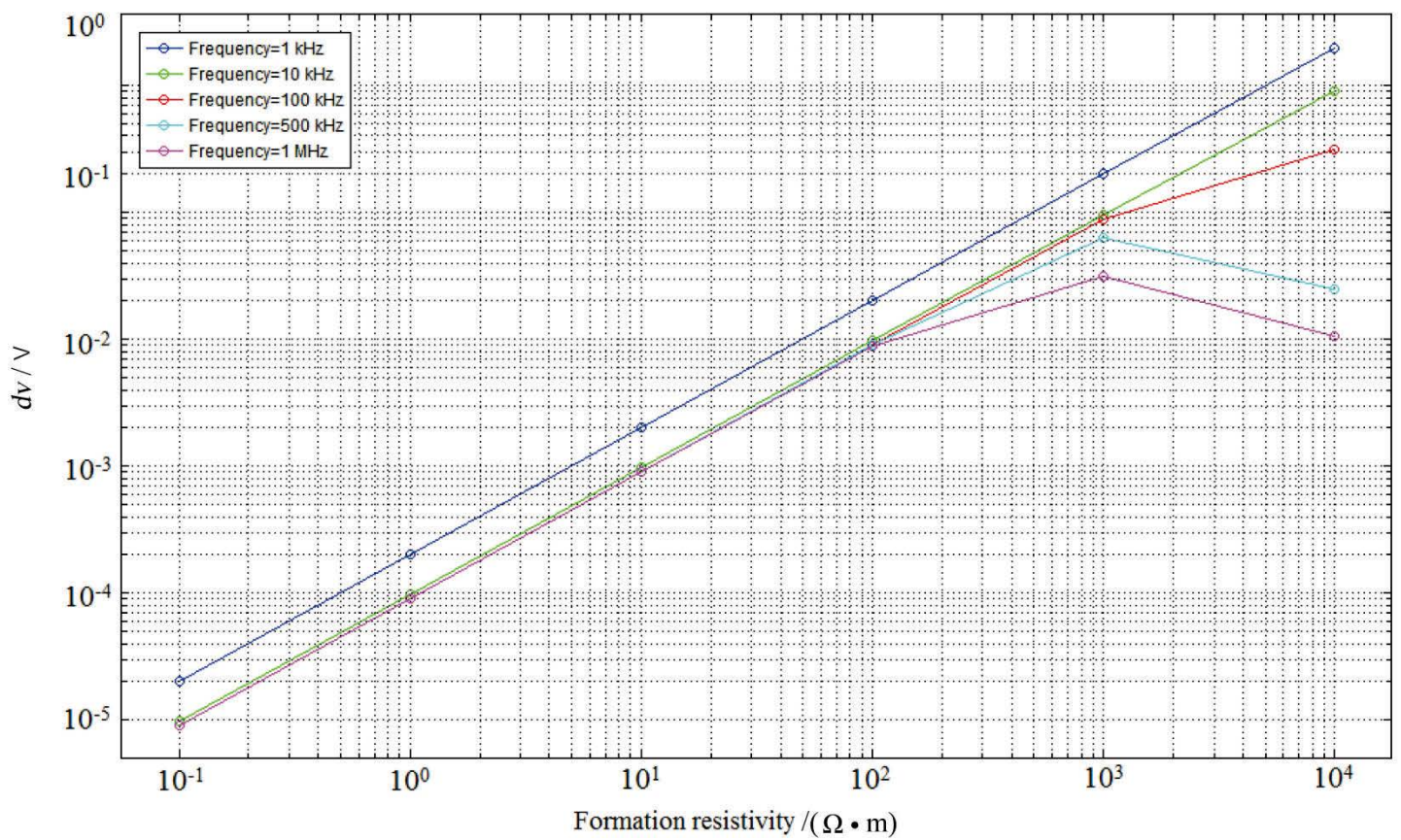

Figure 15. OBIT response versus formation resistivity at different frequencies.

\section{7) Current electrode separation distance vs. penetration depth}

In general, for galvanic methods (e.g. OBIT) used in well logging, the separation distance between current electrodes determines the penetration depth and the separation distance between measurement buttons determines the detection resolution. In this paper, we defined the penetration depth as the distance from the formation surface in which the amplitude of current density reduced by a 
factor 1/e. This definition is analogue to the definition of skin depth for electromagnetic radiation. In order to investigate the penetration depth of the OBIT pad, the amplitude of current density along a red line $(y=0, z=0)$ in Figure 16 has been studied for different pad geometries. The red line starts from the middle of the OBIT pad and the other end is on the exterior boundary of the model.

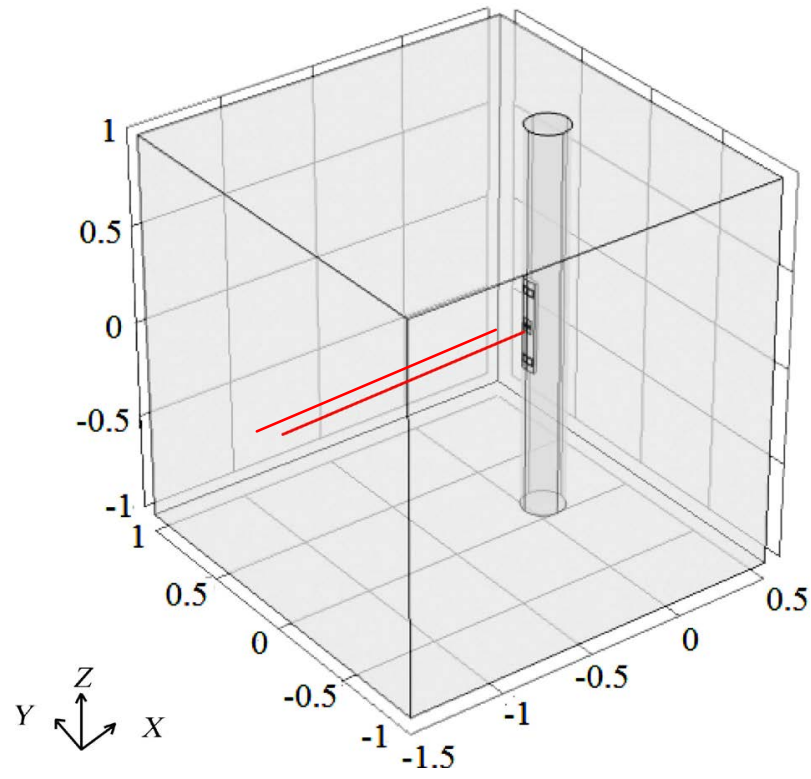

Figure 16. Schematic of the relationship between pad geometry and penetration depth.

The relationship between the current electrode separation distance and the penetration depth has been investigated. Figure 17 shows the amplitude of current density along the red line in Figure 16 for different current electrode

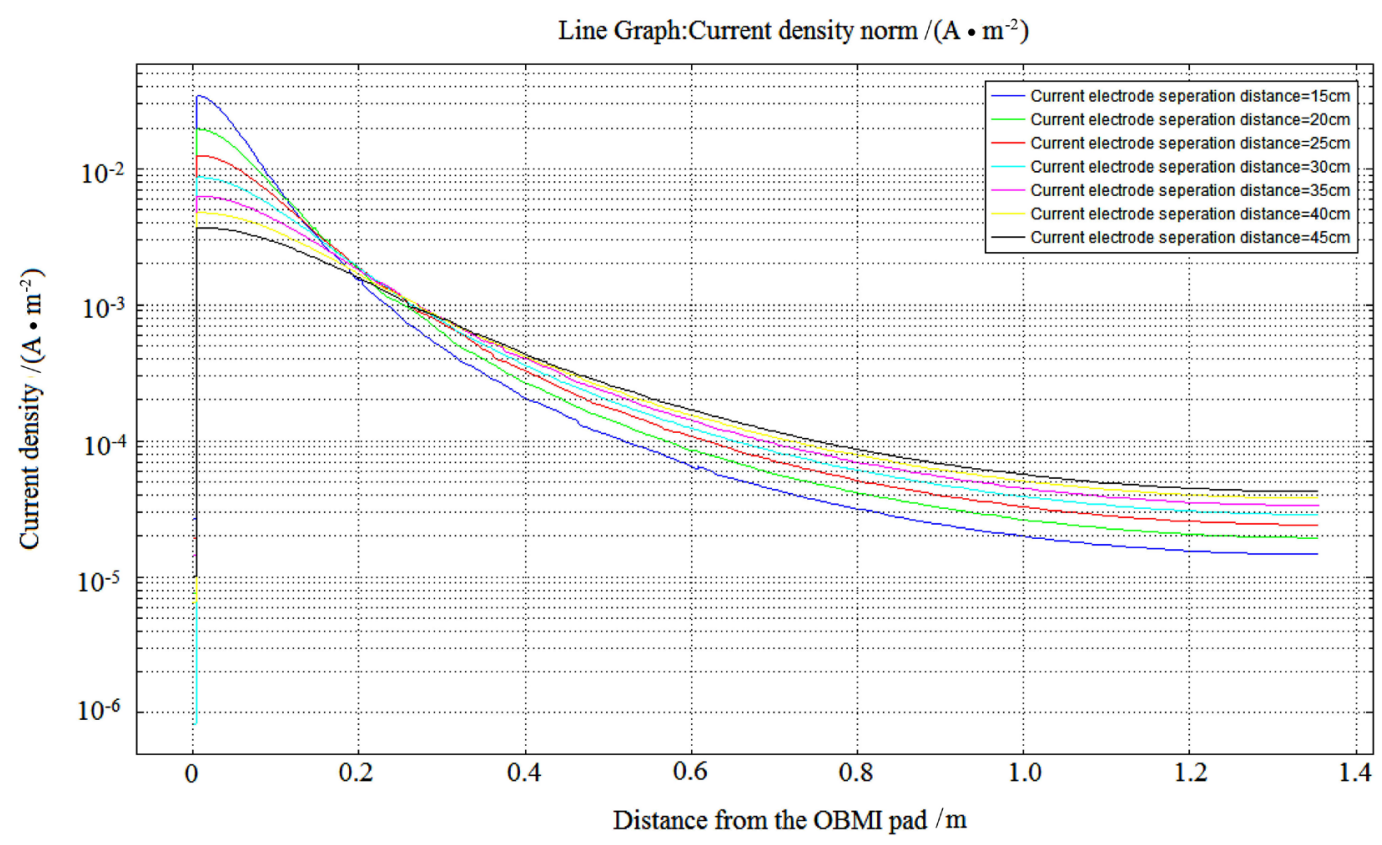

Figure 17. Amplitude of the current density along the red line in Figure 16 for different current electrode separation distances. 
separation distances. The injecting current was kept as $1 \mathrm{~mA}$ for all current electrode separation distances. The frequency was $10 \mathrm{kHz}$. The current electrode separation distances were set to be $15,20,25,30,35,40$ and $45 \mathrm{~cm}$ respectively. The material properties used the values in Table 1. It can be seen from Figure 17 that the current density on the formation wall has the highest value for the smallest current electrode separation distance (i.e. $15 \mathrm{~cm}$ ), but decays the fastest. For the largest current electrode separation distance (i.e. $45 \mathrm{~cm}$ ), the amplitude of the current density on the formation wall has the smallest value, but decays the slowest.

Based on the definition of the penetration depth above, the penetration depths for all current electrode separation distances are calculated and listed in Table 2. From both Figure 17 and Table 2, we can see that the larger the current electrode separation distance is, the larger the penetration depth is.

Table 2. Penetration depth for different current electrode separation distance.

\begin{tabular}{cc}
\hline Current electrode separation distance $/ \mathrm{m}$ & Penetration depth/m \\
\hline 0.15 & 0.0745 \\
0.20 & 0.0983 \\
0.25 & 0.1237 \\
0.30 & 0.1483 \\
0.35 & 0.1721 \\
0.40 & 0.1955 \\
0.45 & 0.2207 \\
\hline
\end{tabular}

\section{8) Formation resistivity versus OBIT detection depth}

Figure 18 shows the amplitude of current density along the red line in Figure 16 for different formation resistivities. It can be seen that the current density

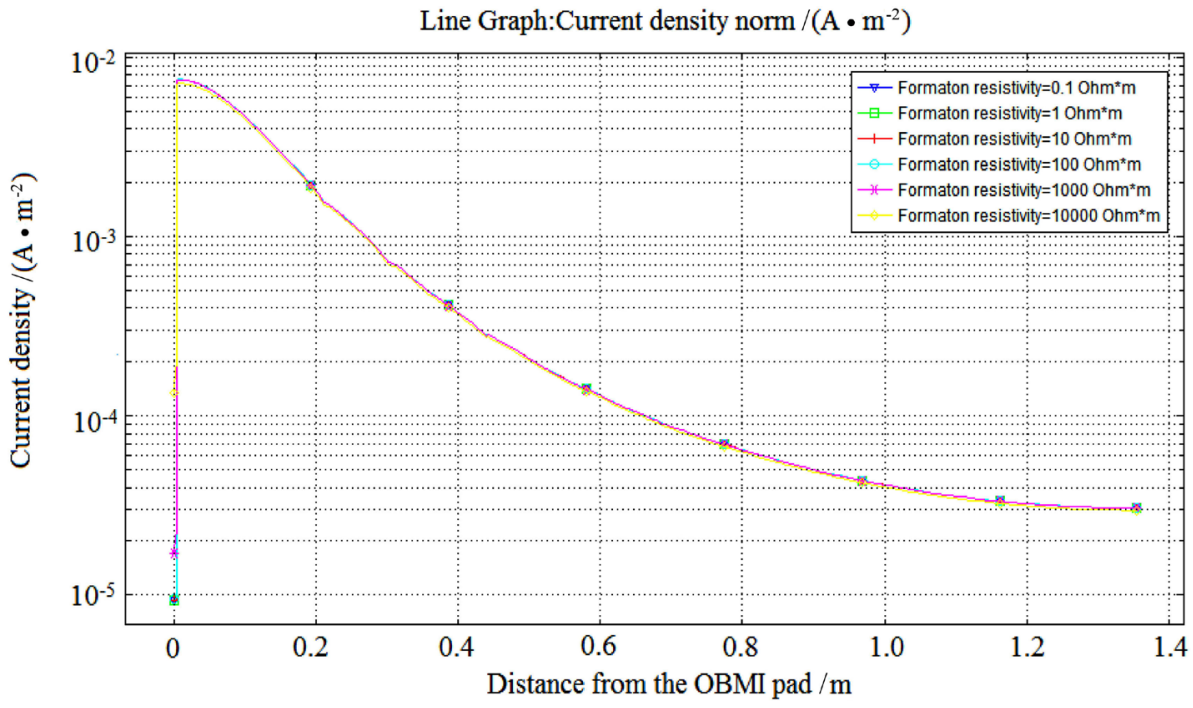

Figure 18. Amplitude of the current density along the red line in Figure 16 for different formation resistivities. 
distribution in the formation has little relevance to the formation resistivity as long as a constant current source was kept on the current electrodes (e.g. $1 \mathrm{~mA}$ in our model). Therefore, the penetration depth is not sensitive to the formation resistivity.

\section{9) Mud electrical properties versus OBIT detection depth}

Figure 19 shows the amplitude of the current density along the red line in Figure 16 for different dielectric constants $(2,4,6,8,10)$ of oil based mud. It can be seen that the amplitude of the current density is bigger for larger dielectric constant than for smaller dielectric constant. That is because large dielectric constant indicates smaller impedance of the oil based mud, and accordingly the amount of current injected into the formation is bigger. However, the decay rates of all curves are very close even though the current densities on the formation wall are different. Since the penetration depth is defined as the decay rate of the current density, the penetration depths for all dielectric constant of the oil based mud are similar. It is worth pointing out that the conclusion that the penetration depth is not sensitive to the formation resistivity and the borehole electrical property is based on the precondition that the injecting current is kept constant.

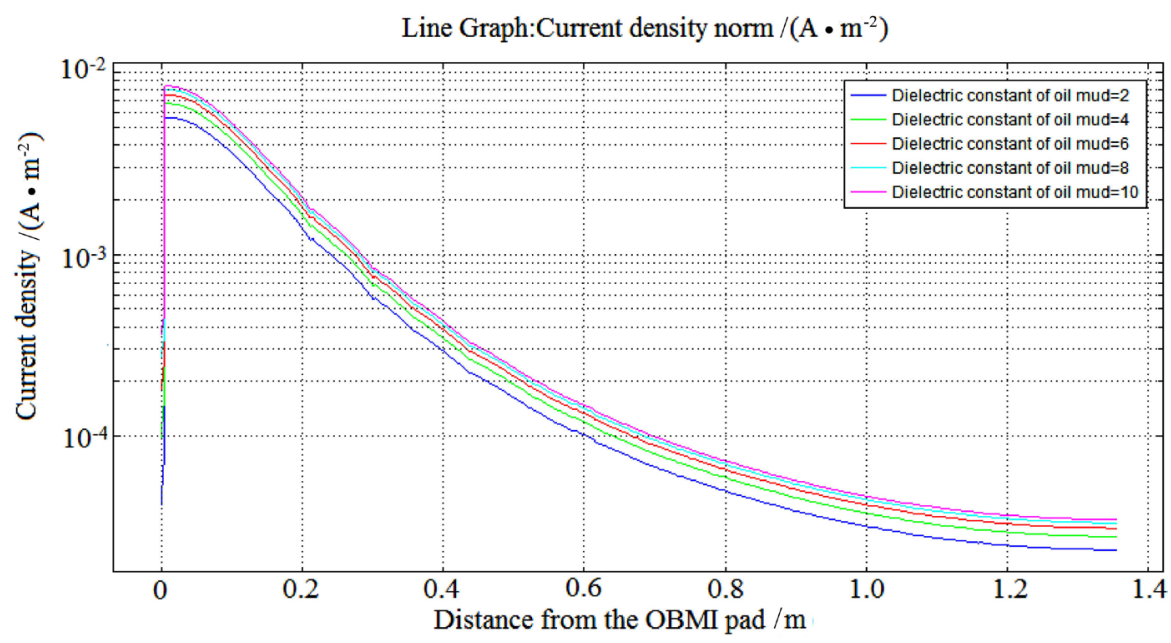

Figure 19. Amplitude of the current density along the red line in Figure 16 for different dielectric constants of oil based mud.

\section{Conclusions}

The four-terminal method was chosen as the measurement principle to design the tool OBIT. A finite-element four-terminal 3-D numerical model was established to study influences of parameters to tool responses. Based on 3-D model, we had quantitatively and qualitatively studied the electric field distribution in the formation and borehole. The influences of tool parameters, such as the area and distance of current-injector electrodes, inject frequency, distance of button sensors, pad standoff and electrical properties of borehole fluid, the tool responses, were simulated and discussed. The 3-D modeling and simulation results have supplied valuable supports for OBIT design and optimization. In summary:

1) The voltage difference on measurement buttons $d v$ is not very sensitive to 
the dimension of current electrodes (length and width) as long as the transmitting current is kept constant. The electrode impedance increases significantly with the decrease of the current electrode size. The higher the electrode impedance is, the higher the voltage on the current electrode is, which is needed in order to keep a constant injecting current. The bigger the diameter of the measurement button is, the better the coupling between measurement buttons and the formation are, the better the tool response is.

2) The OBIT response increases with the increase of the dielectric constant of the mud due to the capacitive impedance between the current electrodes, and the formation surface decreases with the increasing dielectric constant of the oil based mud. The OBIT response decreases with the increase of the mud layer thickness. The OBIT responses at the current frequency from $1 \mathrm{kHz}$ to $10 \mathrm{kHz}$ have good linearity.

3) The larger the current electrode separation distance is, the larger the penetration depth is. The penetration depth is not sensitive to the formation resistivity and borehole electrical property as long as the transmitting current is kept constant.

\section{Conflicts of Interest}

The author declares no conflicts of interest regarding the publication of this paper.

\section{References}

[1] Yang, L., Li, Z., Lu, X.X., et al. (2014) Paleotopographic Characterization and Reconstruction of Karst Reservoirs in Yingshan Formation, Tazhong area, Tarim Basin:a Research Based on Borehole Image Log Interpretation. Acta Petrolei Sinica, 35, 265-275.

[2] Liu, X.J., Liu, K.B., Li, X.L., et al. (2011) Application of Acoustic-Electric Imaging Logging to Yanan Formation Reservoir Exploration in Northern Yanwu Area. Well Logging Technology, 35, 144-150.

[3] Zhang, X., Wang, D.L. and Song, C.A. (2014) Analysis and Application of Texture Based Well Logging Image. Journal of Oil and Gas Technology, 36, 73-77.

[4] Ekstrom, M.P., Dahan, C.A., Chen, M.Y., et al. (1986) Formation Imaging with Microelectrical Scanning Arrays. Proceedings of SPWLA 27 th Annual Logging Symposium, Houston, 9-13 June 1986, SPWLA-1986-BB.

[5] Safinya, K.A., Le Lan, P., Villegas, M., et al. (1991) Improved Formation Imaging with Extended Microelectrical Arrays. SPE Annual Technical Conference and Exhibition, Dallas, 6-9 October 1991, SPE 22726. https://doi.org/10.2118/22726-MS

[6] Xing, X.J., He, S. and Zhou, D.Z. (2016) Appraise and Application of a New Kind of Cleaning Fluid for OBM Cake Removing. Speciality Petrochemicals, 33, 21-23.

[7] Yu, Z.H. (2014) Investigation on Characteristics of Electrical Imaging Tool for Oil-Base Mud Based on Capacitive Coupling. Well Logging Technology, 38, 206-210.

[8] Wang, H.Z., Lu, D.W., Zhang, X.Y. and Sun, J.M. (2011) An Overview of Recent Advances in Well Logging Technology. Progress in Geophysics, 20, 786-795.

[9] Li, Q.S., Pan, H.P. and Zhang, R. (2005) THE Progress of Resistivity Imaging Log. 
Chinese Journal of Engineering Geophysics, 2, 304-310.

[10] Chemung, P., Cook, G., Flournoy, G., et al. (2001) A Clear Picture in Oil Based Mud. Oil Field Review, Winter 2001/2002, 1-27.

[11] Hayman, A.J. and Cheung. P. (2007) Formation Imaging While Drilling in Non-Conductive Fluids. US Patent: 7,242,194 B2.

[12] Cheung, P., Pittman, D., Hayman, A., et al. (2001) Field Test Results of a New Oil-Base Mud Formation Imager Tool. Transactions of the SPWLA 42nd Annual Logging Symposium, Houston, 17-20 June 2001, Paper XX.

[13] San Martin, L., Kainer, G., Paul Elliott, J., et al. (2008) Oil-Based Mud Imaging Tool Generates High Quality Borehole Images in Challenging Formation and Borehole Condition, Including Thin Bed, Low Resistive Formation and Shales. SPWLA 49th Annual Logging Symposium, Austin, 25-28 May 2008, SPWLA-2008-KKKK.

[14] Evans, M.T. and Norwich, G.B. (2003) Apparatus and Method for Wellbore Resisitivity Determination and Imaging Using Capacitive Coupling. US Patent: 6,600,321 B2.

[15] Bloemenkamp, R., Zhang, T.H., et al. (2014) Design and Field Testing of a New High-Definition Microresistivity Imaging Tool Engineered for Oil-Based Mud. SPWLA 55th Annual Logging Symposium, Abu Dhabi, 18-22 May 2014, SPWLA-2014-KK.

[16] Itskovich, G., Corley, B., Forgang, S. and Le, F. (2014) An Improved Resistivity Imager for Resistivity Imager for Oil-Based Mud: Basic Physics and Applications. SPWLA 55th Annual Logging Symposium, Abu Dhabi, 18-22 May 2014, SPWLA-2014-NN. 